\title{
Aplicação do Método SLP no desenvolvimento de um layout otimizado em uma empresa têxtil
}

\author{
William José Borges \\ Instituto Federal de Santa Catarina (IFSC) \\ (william.borges@ifsc.edu.br) \\ Cassiano Rodrigues Moura \\ Instituto Federal de Santa Catarina (IFSC) \\ (cassianocrm@hotmail.com) \\ Edson Meincheim \\ Instituto Federal de Santa Catarina (IFSC) \\ (edsonm@weg.net) \\ Giovani Conrado Carlini \\ Instituto Federal de Santa Catarina (IFSC) \\ (giovani.carlini@ifsc.edu.br) \\ Luana de Oliveira \\ Instituto Federal de Santa Catarina (IFSC) \\ (luanasc86@gmail.com)
}

\begin{abstract}
Resumo: A indústria têxtil tem buscado fortemente se manter competitiva no mercado, sendo que um dos seus maiores desafios é a busca pela eficiência na produtividade. Diante disso, o desenvolvimento de um Layout otimizado pode contribuir para a melhoria das atividades das organizações, gerando benefícios para a competitividade. Com isso, o objetivo deste trabalho é desenvolver a metodologia SLP - Systematic Layout Planning para buscar um novo Layout para uma indústria da área têxtil, alinhando a eficiência produtiva aos conceitos de qualidade nos produtos acabados. A metodologia adotada no desenvolvimento deste estudo manteve uma abordagem qualitativa. Já a coleta de dados foi realizada por meio de entrevistas e questionários. Como resultado, constatou-se a importância de se analisar os modelos de layouts produtivos, visto que os resultados atingidos foram de extrema importância para a concordância do trabalho com os objetivos gerais da empresa. Os resultados apresentam as características do novo Layout que foi projetado, de modo a utilizar o espaço disponível, onde foi possível manter os corredores dentro do estabelecido pela norma, além de projetar os maquinários e postos de trabalho de modo a promover um fluxo mais objetivo e eficiente, reduzindo, assim, a movimentação desnecessária de materiais e pessoas.
\end{abstract}

Palavras-Chaves: Layout; SLP; Industria têxtil; Otimização.

\section{Aplication of the SLP Method in the development of an optimized layout in a textile company}

Abstract: The textile industry has strongly sought to remain competitive in the market and one of its biggest challenges is the pursuit of productivity efficiency. Thus, the development of an optimized layout can contribute to the improvement of the activities of organizations generating benefits for competitiveness. Thus, the objective of this work is to develop the Systematic Layout Planning (SLP) methodology to seek a new layout for a textile industry aligning the productive efficiency with the concepts of quality in the finished products. The methodology adopted in the development of this study maintained a qualitative approach. Data collection was performed through interviews and questionnaires. As a result, it was found that the importance of analyzing the productive layout models, since the results achieved were extremely important for the agreement of the work with the general objectives of the company. The results present the characteristics of the new Layout that was designed to use the available space, where it was possible to keep the corridors within the established standard besides designing the machines and workstations to promote a more objective and efficient flow, thus reducing unnecessary movement of materials and people.

Keywords: Layout; SLP; Textile industry; Optimization. 


\section{INTRODUÇÃO}

Nesse mercado global marcado por disputas acirradas e diante da competitividade empresarial imposta pelo mercado cada vez mais globalizado, em que, cada vez mais, as empresas deixam de ser apenas locais e procuram competir no mercado internacional, um dos maiores fatores que influem neste ponto é a produtividade (TROCHE-ESCOBAR, et al., 2015). A produtividade de uma indústria representa sua capacidade de atingir seus objetivos, e, diante da competitividade, a produtividade tende a ser cada vez maior, com os menores recursos possíveis. Como consequência, a produtividade pode ser traduzida como sendo a capacidade de se fazer mais com menos.

O cenário atual, de alta competitividade e com cada vez mais produtos oriundos do mercado asiático entrando no mercado brasileiro, faz com que as indústrias busquem processos cada vez mais otimizados, visando à redução de seus custos de produção, aumentando suas margens de contribuição e o máximo em qualidade e produtividade; gerando condições de terem preços mais competitivos e se manterem no mercado.

Isso quer dizer que uma empresa que tem por objetivo se destacar em um mercado cada vez mais competitivo necessita permanentemente buscar as melhorias contínuas de seus processos, visando cada vez mais ao aumento de sua produtividade. $O$ aumento da produção sem que haja investimentos em recursos transformadores e mão de obra é a busca pela excelência em produtividade. Isso exige a habilidade em identificar os desperdícios ocultos dentro do processo de fabricação.

Existe uma grande parcela das indústrias de confecções de pequeno e médio porte que estão defasadas tecnologicamente. O desenvolvimento tecnológico, nessas indústrias, não vem acompanhando a mesma velocidade que se apresenta em empresas de grande porte no mesmo setor. A defasagem tecnológica torna seus processos produtivos defasados, prejudicando sua eficiência e, consequentemente, sua competitividade diante do mercado globalizado. Dentre todos os problemas possíveis de competição, um que se destaca e pode prejudicar a competição da empresa está relacionado à escolha do Layout produtivo.

A escolha de um modelo de Layout que melhor se adapte à realidade do processo produtivo da empresa tende a diminuir a movimentação de pessoas e 
materiais entre os postos de trabalho aumentando assim o fluxo da produção. Busca também influenciar o nível de estoque em processo, bem como no tamanho dos lotes de transferência, facilitando o gerenciamento das atividades, entre outros. $O$ Layout, quando implantado de maneira correta, propicia que os funcionários exerçam suas atividades com mais satisfação, consequentemente havendo um aumento de produtividade. O estudo dos Layouts produtivos que visem à otimização dos recursos de produção são fundamentais na busca pela eficiência dos processos produtivos.

Conforme descrito por Oliveira et al., (2017), através da melhoria no arranjo físico, pode-se proporcionar uma melhoria da eficiência das operações produtivas. Em seus estudos, o autor apresenta a eficácia do rearranjo de uma estrutura fabril, por meio do balanceamento de linha, alinhando a melhoria do arranjo físico como estratégia de adequação da capacidade, evidenciando que, quando a linha de montagem está devidamente balanceada, bem como quando acompanhada de arranjo físico melhorado, pode-se reduzir os desperdícios, permitindo às indústrias aumentar sua competitividade. Conforme descrito por Make, Rashid \& Razali (2017), o balanceamento de linha de produção define quantas estações de trabalho a linha terá e quais tarefas atribuir a cada uma, sendo que o objeto do balanceamento é reduzir o número de estações de trabalho dado um tempo de ciclo ou diminuindo o tempo de ciclo dado o número de estações de trabalho.

Nesse contexto, o presente trabalho se volta ao estudo da seguinte problemática: resolver o problema apresentado pela empresa, buscando aumentar a qualidade do corte dos tecidos e aumentar a eficiência produtiva, através do desenvolvimento de um novo Layout produtivo, a fim de atender seus objetivos. Diante do exposto, o objetivo geral deste trabalho é desenvolver a metodologia $S L P$ - Systematic Layout Planning para estudar e buscar um novo Layout, de forma a otimizar o processo produtivo de uma indústria da área têxtil. 


\section{REFERENCIAL BIBLIOGRÁFICO}

\subsection{A administração da produção no contexto dos layouts produtivos}

Com o passar dos anos, muitos modelos administrativos passaram a ser utilizados pelas indústrias. No entanto, o tratamento científico dado pelas mais variadas correntes de pensamentos não segue o mesmo delineamento técnico, daí a importância de trabalhar os conceitos e desmembramentos da Administração da Produção. Slack et al. (2006), por exemplo, trabalha a administração da produção como sendo uma atividade de gerenciar recursos destinados à produção e disponibilização de bens e serviços.

Ao considerar a Ciência como a arte de se converter os elementos complexos da organização em uma estrutura capaz de atingir os objetivos da empresa pela otimização de custos e a geração de lucros, entende-se que a Administração da Produção pode ser trabalhada como Ciência, pois compreende sistematizações em torno de problemas, objetivos, atitudes e conhecimentos (GRAEMI; PEINADO, 2007).

Seguindo essa caracterização da ciência a partir da Administração da Produção, é possível identificar objetivos que circundam as mudanças produtivas. $\mathrm{O}$ primeiro grande objetivo que se pode visualizar nas mudanças de Layout são as facilidades físicas ocasionadas na fábrica. Essas mudanças são capazes de alterar os meios de produção em nível material, tecnológico, humano, capital e patrimonial, ou seja, abrange mudanças ao longo de todos os recursos produtivos das organizações. O arranjo físico de uma instalação produtiva tem o propósito de unir recursos transformadores de forma eficiente, para que as atividades industriais trabalhem de forma organizada, a fim de obter um desempenho, garantindo a eficiência produtiva (GIRALDELI et al., 2018).

Outro benefício, tratado por Chiavenato (2014), se refere à procura das empresas em alcançar objetivos específicos. Para o autor, os objetivos empresariais possuem essencialmente quatro funções, sendo elas: mostrar uma situação futura, indicando a direção que a empresa deve seguir; compõem uma fonte de legitimidade, justificando a existência da empresa e também as atividades a serem seguidas; servem como padrões, conferindo condições de ser comparada e avaliada 
o seu êxito; e servem como unidade de medida, possibilitando a verificação e comparação dos resultados de produtividade.

O Layout, quando implantado de maneira correta e em sintonia com os objetivos da empresa, tende a apresentar bons resultados no clima organizacional e produtivo. Quando os produtos a serem fabricados e os processos produtivos são estudados e planejados anteriormente à implantação, os objetivos previamente especificados possuem grande potencial de serem alcançados. $O$ Layout, quando desenvolvido sobre direcionamento técnico, pode contribuir positivamente com estes objetivos, uma vez que este tem influência direta em seu processo produtivo (ASSUNPÇÃO \& JACOBS, 2019).

O objetivo da eficiência, desenvolvido há anos pela escola científica, busca, cada vez mais, melhorar seus processos produtivos, e está a cada dia buscando maneiras de aumentar seus resultados operacionais. Para Martins e Laugeni (2015), se o Layout for implantado de maneira correta, atendendo as mudanças de mercado, produtos, entre outros, propiciam uma grande satisfação no trabalho aos funcionários, fazendo com que as pessoas envolvidas no processo produtivo se sintam parte do processo de transformação e cumprimento dos objetivos da empresa.

Da mesma forma, quando os Layouts são projetados de forma a otimizar processos e primar pela eficiência, esses assumem papel importante na empresa do ponto de vista organizacional e funcional. A disposição das máquinas e equipamentos de maneira harmônica geram uma boa aparência na área de trabalho tanto para os funcionários como para os clientes. Há consequentemente uma maior produção em um menor tempo, otimização de espaço e deslocamento, redução dos manuseios durante o processo de transformação, ajustamento mais fácil às mudanças, redução de fadiga na execução de tarefas, entre outros benefícios.

Outro importante destaque nos Layouts se refere à definição do tipo de produção/produto que a empresa está trabalhando. A correta identificação do modelo produtivo proporciona uma melhor supervisão aos gestores, sendo possível acompanhar a rotina de trabalho e tomar ações imediatas para minimização de problemas. Há também diminuição de riscos para a saúde e segurança do funcionário, adaptação de ambientes adequados quanto à ventilação, temperatura, iluminação, ruídos, entre outros fatores de produção. Esses fatores de produção são 
considerados no momento em que a organização define o modelo de Layout que será empregado na fábrica.

\subsection{Layouts produtivos}

Os modelos de Layout sugeridos por autores como Assunpção e Jacobs (2019); Slack et al. (2015); Martins e Laugeni (2015); Chiavenato (2014); Peinado e Graeml (2007) e Corrêa e Corrêa (2017), podem ser categorizados em cinco grandes grupos, envolvendo pessoas, máquinas, processos e produtos. As escolhas envolvendo esses fatores de produção têm o potencial de induzir a eficiência produtiva e, com isso, melhorar o desempenho das organizações. Dessa forma, os grupos convencionais trabalhados na literatura são: por produto, celular, posicional, mistos e processo.

\subsubsection{Layout por produto}

O arranjo físico por produto visa dispor os recursos transformadores seguindo um fluxo pré-definido dentro do processo de produção. Os objetos de análise (produto, cliente ou informação) passam por um posto de transformação e, depois de concluída determinada etapa, seguem até o próximo posto de transformação. Os autores comentam ainda que esse modelo de arranjo pode receber outros nomes, tais como arranjo físico em ñfluxoòou em ñinhaò(SLACK et al., 2015).

De acordo com Peinado e Graeml (2007), o arranjo em linha não necessariamente segue o conceito de uma linha reta, pode ser disposto também em ñò ou r̃́sò de forma a ser praticado em função do espaço físico disponível na empresa. Essas estruturas no Layout podem ser visualizadas na Figura 1. Segundo Martins e Laugeni (2015), nesse modelo de arranjo os recursos transformadores são dispostos seguindo uma sequência de operações, sem que haja caminhos alternativos. Para o autor, esse modelo de arranjo é indicado para produção com mínima ou nenhuma diversificação de produto. 
Figura 1: Modelagem produtiva utilizando os Layouts por produto em r̃òe em î́sò

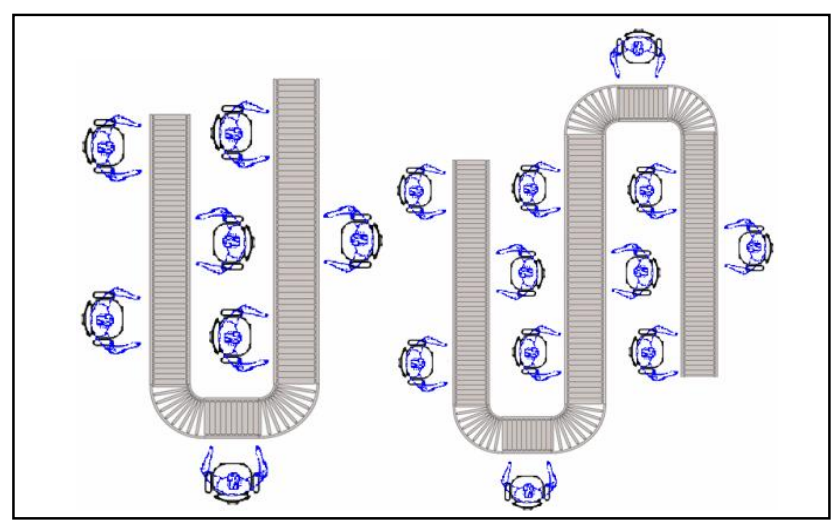

Fonte: Adaptado de Peinado e Graeml (2007)

\subsubsection{Layout celular}

No Layout celular, também chamado de célula de manufatura, conforme ilustrado na Figura 2, o produto é fabricado/transformado por completo em um único local, que compreende todas as máquinas e equipamentos necessários para fabricação/transformação do mesmo, este tem um potencial de reduzir as movimentações na fábrica (SOULÉ et al., 2016; MARTINS e LAUGENI, 2015). A principal característica desse arranjo físico é a flexibilidade por tamanho de lotes, permitindo altos níveis de qualidade e produtividade. Ainda de acordo com os autores, os materiais se deslocam dentro de uma célula buscando os processos necessários.

O produto, ao entrar em uma célula, sofre toda transformação necessária até estar pronta para o envio a próxima célula. Slack et al. (2015) complementa que, após o produto ser processado em uma célula, o mesmo pode seguir para outra célula sofrendo outro processo de transformação.

Figura 2: Modelagem produtiva utilizando o Layout celular

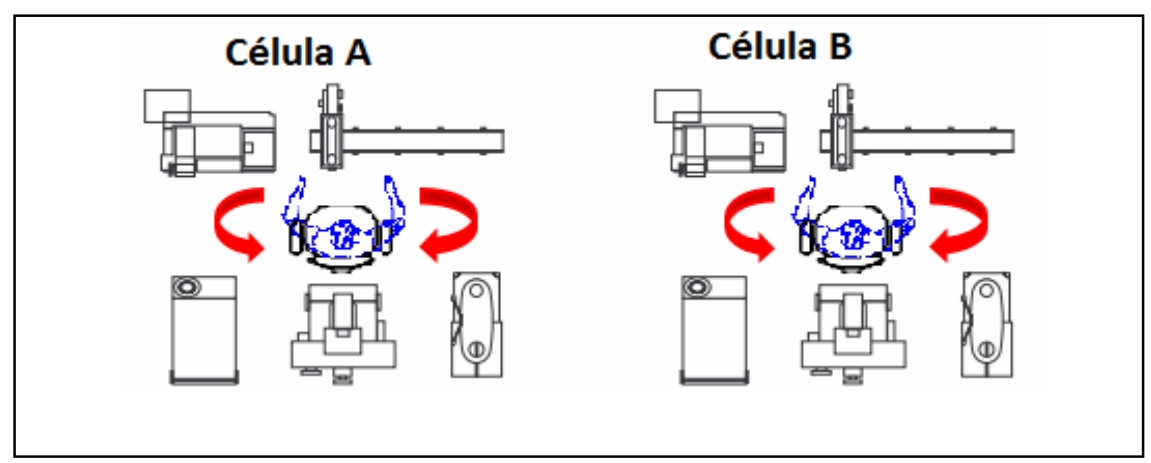

Fonte: Adaptado de Peinado e Graeml (2007) 


\subsubsection{Layout posicional}

De acordo com Slack et al. (2015), no arranjo físico posicional, ou arranjo físico de posição fixa, quem se move são os recursos transformadores, ao invés dos recursos transformados. Esse tipo de arranjo é oposto ao arranjo físico por produto, pois é empregado esse tipo de arranjo nos casos em que os produtos a serem fabricados são muito grandes, ou serão transformados em locais remotos.

Esse tipo de arranjo posicional é empregado em estaleiros, fabricação de rodovias e ferrovias, pontes, usinas, geradores, construção de edifícios e grandes civis, fabricação de aviões entre outros produtos de grandes dimensões físicas.

Com o auxílio da Figura 3, é possível observar a demonstração dos recursos transformadores movimentando-se ao redor do recurso transformado. Segundo Peinado e Graeml (2007), as vantagens desse tipo de arranjo são que não ocorrem a movimentação do produto, e as empresas podem optar pela terceirização do projeto ou parte dele dependendo da complexidade de fabricação.

Figura 3: Arranjo Físico Posicional

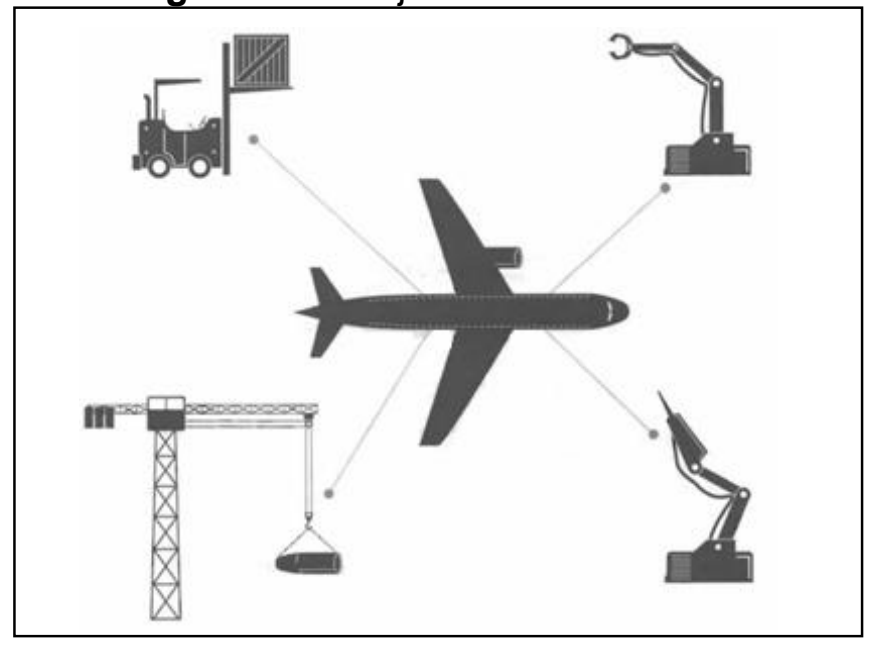

Fonte: Martins e Laugeni (2015)

\subsubsection{Layout misto ou combinado}

Martins e Laugeni (2015) definem que, no Layout combinado, como o próprio nome diz, há uma combinação de arranjos, objetivando-se a obtenção das vantagens de todos os demais tipos de arranjos. Na maioria das vezes, é utilizada a combinação dos arranjos celulares, do arranjo por processo e do arranjo por produto na elaboração desse modelo de Layout. A combinação desses movimentos culmina 
em um arranjo físico misto, deixando interagir os demais tipos de arranjos apresentados. A Figura 4 mostra a utilização de um Layout em linha sendo complementada pela utilização de quatro células produtivas.

Figura 4: Layout Misto

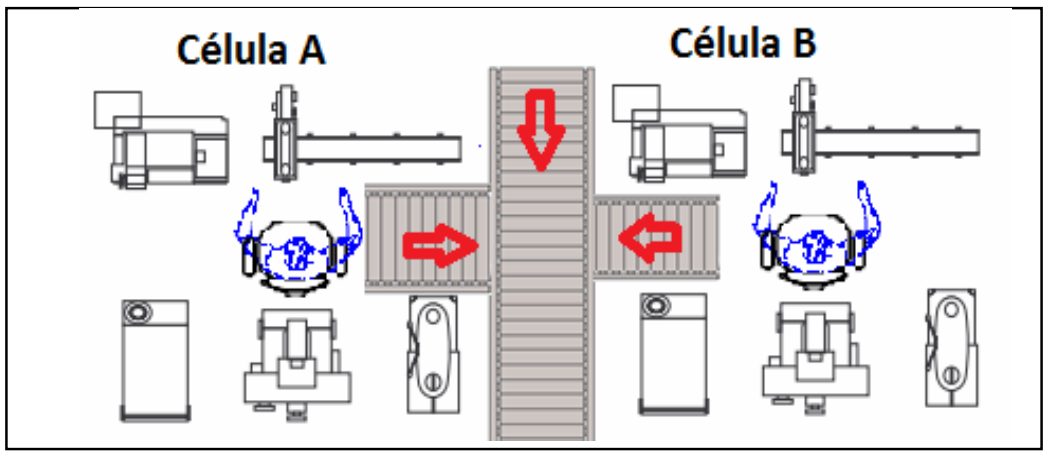

Fonte: Adaptado de Peinado e Graeml (2007)

\subsubsection{Layout por processo}

No Layout por processo, também chamado de funcional, Martins e Laugeni (2015) e Corrêa e Corrêa (2017) destacam que máquinas, equipamentos, recursos ou serviços com similaridades são agrupados na mesma área. Slack et al. (2015), compartilham da mesma ideia complementando que pode haver o agrupamento também de processos similares ou com necessidades similares. Nesse modelo de arranjo físico, o caminho percorrido pelo material dentro de um fluxo é definido, sendo que os mesmos se deslocam de uma etapa até a outra buscando os diversos processos como pode ser observado na Figura 5.

Figura 5: Layout por Processo ou Funcional ï Fluxo de Materiais

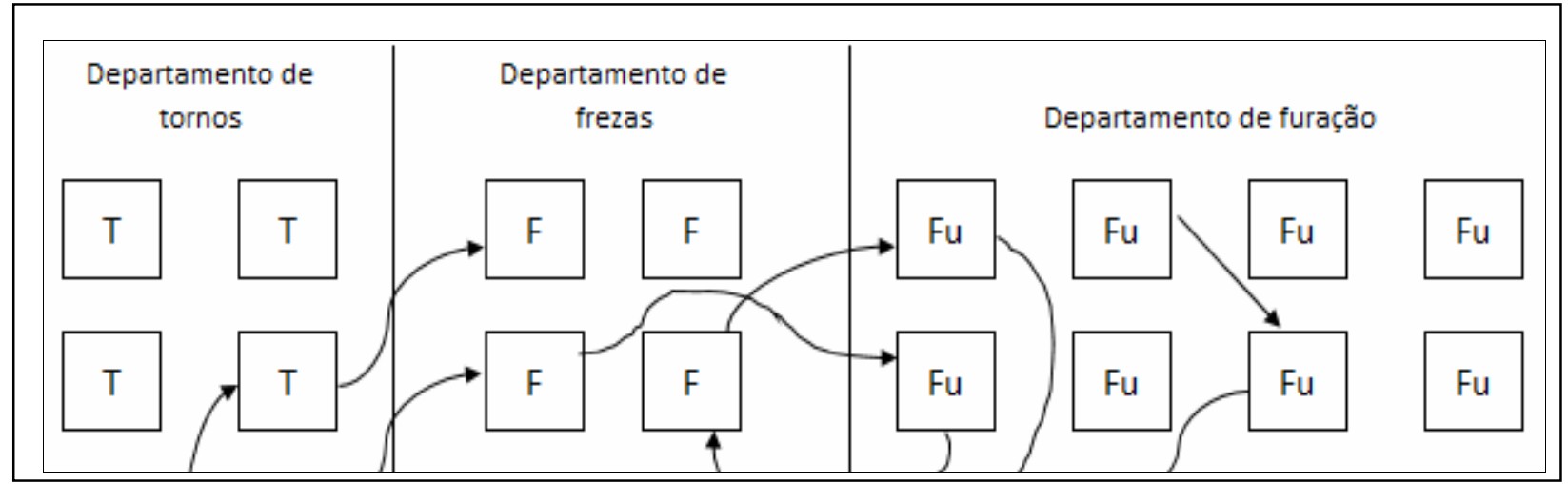

Fonte: Adaptado de Martins e Laugeni (2017) 


\subsection{Método SLP ñ Systematic Layout Planning Systematic Layout Planning}

O sistema SLP (Systematic Layout Planning) é uma ferramenta utilizada para o planejamento e desenvolvimento de arranjos físicos, tendo como finalidade alcançar a máxima eficiência possível do processo produtivo. De acordo com Corrêa e Corrêa (2017), o sistema SLP é utilizado para o desenvolvimento de um bom Layout, sendo esse sistema proposto nos anos 50 e destacado por Muther (1978) como um método sistemático de análise de projeto de arranjo físico por processo. $O$ SLP desenvolve-se em etapas conforme apresentadas no Quadro 1, onde se observa os passos a serem seguidos no desenvolvimento do método, bem como suas respectivas ferramentas.

Quadro 1: Passos do método SLP

\begin{tabular}{|l|l|}
\hline \multicolumn{1}{|c|}{ Passos } & \multicolumn{1}{c|}{ Possíveis ferramentas } \\
\hline $\begin{array}{l}\text { 1. Análise de fluxos de produtos ou } \\
\text { recursos }\end{array}$ & Diagrama de fluxo ou diagrama r̃de-paraò \\
\hline $\begin{array}{l}\text { 2. Identificação e inclusão de fatores } \\
\text { qualitativos }\end{array}$ & Diagrama de relacionamento de atividades \\
\hline $\begin{array}{l}\text { 3. Avaliação dos dados e arranjo de áreas } \\
\text { de trabalho }\end{array}$ & Diagrama de arranjo de atividades \\
\hline $\begin{array}{l}\text { 4. Determinação de um plano de arranjo } \\
\text { dos espaços }\end{array}$ & Diagrama de relação de espaço \\
\hline 5. Ajuste do arranjo no espaço disponível & Planta do local e modelos (templates) \\
\hline
\end{tabular}

Fonte: Corrêa e Corrêa (2017)

\section{METODOLOGIA}

Este trabalho foi desenvolvido através de uma pesquisa qualitativa, que, de acordo com Flick (2009), tem por objetivo descobrir o que há de novo, para em seguida iniciar o desenvolvimento de teorias empiricamente fundamentadas. No presente trabalho essa metodologia foi adotada porque proporcionou uma maior aproximação entre a pesquisa e a empresa em estudo. Como o propósito dessa análise foi compreender como estão estruturados os processos produtivos dentro da empresa, bem como obter informações necessárias para o desenvolvimento do estudo visando atingir os objetivos descritos nesse trabalho, a pesquisa foi realizada com o gerente geral de produção.

O método de pesquisa utilizado foi o estudo de caso. Conforme Yin (2014), o 
estudo de caso é caracterizado pelo profundo e exaustivo estudo dos fatos objetos de investigação, permitindo um amplo conhecimento da realidade e dos fenômenos pesquisados. A pesquisa de estudo de caso é encarada como uma forma menos desejável de investigação do que levantamentos ou experimentos devido a, por exemplo, disponibilizar pouca base para generalização científica, ao que contraargumenta o autor: os estudos de caso são, sim, generalizáveis a proposições teóricas (generalização analítica), embora não a populações ou universos (generalização estatística).

Como o objetivo dessa pesquisa se voltou para a escolha de uma modelagem qualitativa, a pesquisa também remete ao tipo descritivo, pois descreveu e forneceu as informações de como se apresenta a empresa. Assim, a pesquisa descritiva realizada contribuiu para se obter na íntegra os dados da empresa, alinhados com o objetivo proposto, sem manipulá-los, dando condições aos autores da realização das análises necessárias para o desenvolvimento desse trabalho.

O fluxo da pesquisa contou com dados primários e secundários, e se caracterizou por ser exploratória. Os dados primários, obtidos através da pesquisa semiestruturada, foram coletados de forma aberta com o gerente geral da empresa. Através destes, pôde-se iniciar a aplicação do método SLP, seguindo as etapas propostas por Corrêa e Corrêa (2017). É importante ressaltar que este projeto, considerado piloto, foi aplicado apenas em uma área, especificamente no setor onde acontece o processo de corte de tecidos da empresa.

\section{DESENVOLVIMENTO}

\subsection{Situação atual da empresa}

A empresa em estudo atua no ramo da confecção e tem grande destaque na indústria nacional. Atualmente, está presente em todos os estados brasileiros, levando suas criações a 1.300 lojas multimarcas. A empresa tem capacidade produtiva de cinquenta mil peças por coleção, que podem ter variação de cores e tamanhos, sendo que anualmente quatro coleções são criadas.

Em relação ao processo produtivo, a empresa utiliza da terceirização para realização de alguns processos produtivos, sendo que atualmente é terceirizado 
cerca de $80 \%$ de sua produção. A empresa conta atualmente com cerca de 80 funcionários que se dividem nas áreas administrativas e fabril, especificamente no setor onde o processo de corte está inserido, há ao todo nove funcionários.

Ultimamente a empresa enfrenta alguns problemas que causam atraso da produção. Pode-se destacar alguns, como: as perdas que são geradas no processo de corte, problemas no processo de lavagem na lavanderia, e algumas peças que podem chegar da costura terceirizada com problemas de encaixe devido ao corte ter sido realizado de maneira ineficiente. Como a empresa preza pela qualidade de seus produtos e satisfação de seus clientes, ela constantemente busca evoluir em seus processos e busca pela redução dos custos de produção, esse é um dos motivos que a motivou a buscar alternativas, trazendo e aumento de eficiência e consequentemente qualidade para os produtos.

No setor de corte (ver Figura 6), onde especificamente foi realizado 0 trabalho, pode-se observar alguns problemas relacionados ao Layout, entre eles destacam-se, dificuldade de movimentação de itens relacionados ao processo de produção, problemas relacionados à ergonomia dos funcionários e excesso de movimentação de itens em processo.

Figura 6: Local de aplicação ï Setor de corte

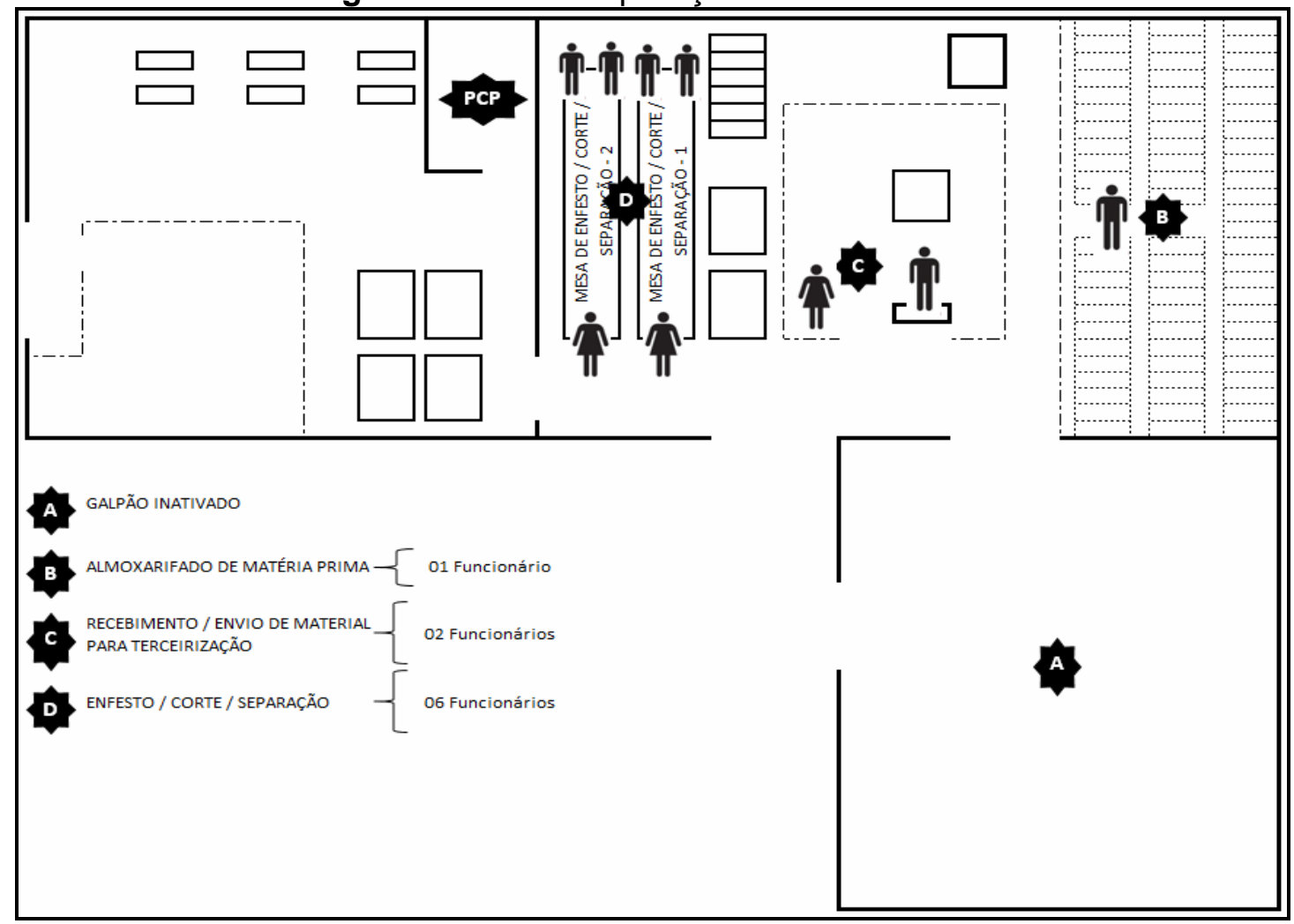

Fonte: Autores (2019) 
Referente à eficiência produtiva, na empresa o controle é realizado considerando o total de peças por coleção, dividindo-se pelo número de dias úteis disponíveis nos três meses (63 dias úteis). De posse desse valor, dividem pela quantidade de minutos disponíveis em um turno de trabalho (528 minutos). resultado é a meta diária que deverá ser produzida. Com base nesse valor, o controle da eficiência é monitorado diariamente.

Para determinação dos estudos e análises, foram tomados como base os dados de um dia de produção da empresa, sendo os dados caracterizados como dados primários. Como a empresa possui um mix variado de produtos, não há uma constante de peças a serem produzidas por ordens, onde acabam sendo geradas ordens com poucas peças, bem como comprimento de enfesto pequeno. Isso faz com que o balanceamento da produção e otimização dos recursos sejam difíceis de serem realizados.

\subsection{Estudo do Layout - SLP}

Para o estudo do novo Layout da empresa, foi analisada a quantidade de peças movimentadas em um dia de produção, sendo esta a quantidade de peças movimentadas desde a máquina de corte até o setor de costura interno, onde algumas peças são produzidas.

A análise dos fluxos foi construída de modo a obter a relação r̃de-paraòdentro do fluxo já conhecido, sendo caracterizado em Enfesto/Corte (E/C), Mesa de separação (MS), Máquina de Debrum, Caseadeira, Etiqueta (MDCE), Pallets de mercadorias para envio à terceiros (PET) e Setor de Costura interno (SCI).

A Figura 7 mostra no diagrama r̃de-paraò para um dia de produção, onde foram cortadas 796 peças, sendo que após o corte foram encaminhados para a MS. $\mathrm{Na}$ MS foram separadas em três lotes, sendo que um lote com 398 peças passaram pela MDCE, 318 peças foram separadas e enviadas para os PET e 80 peças foram enviadas para o SCI. Das 398 peças que passaram pela MDCE, 318 peças após processadas foram enviadas para os PET e 80 peças foram enviadas para o SCl. Seguindo o fluxo de produção, as 636 peças que estavam nos PET foram enviados aos terceiros. O SCI recebeu um total de 160 peças para produção. O resultado dessa movimentação gerou um fluxo diário que pode ser observado na soma dos fluxos (Ver Figura 7). 
Aplicação do Método SLP no desenvolvimento de um layout otimizado em uma empresa têxtil

Figura 7: Diagrama r̃deï paraòda análise de fluxos das peças

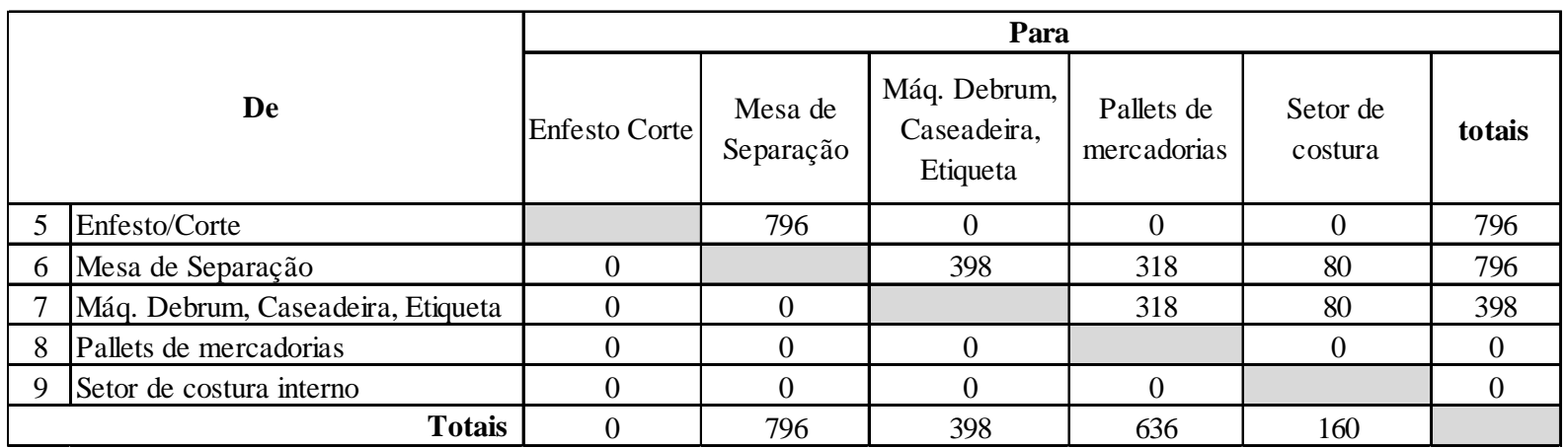

Fonte: Autores (2019)

Com base nos fluxos, estabeleceram-se as prioridades para proximidades. Apresentou-se um maior fluxo entre o E/C e a MS, ocorrendo a movimentação das 796 peças, mostrando que todas as peças após o corte passam pela MS. Esse fluxo foi classificado como ñÀ̀ onde se tem a proximidade absolutamente necessária. $O$ segundo maior fluxo apresentou o envio de 398 da MS para as MDCE, isso resultou em uma classificação r̂́tò que significa uma proximidade especialmente necessária. A mesma classificação r̃Eòfoi dada para o fluxo da MS para os PET que movimentou 318 peças e também das MDCE para os PET, que apresentou a mesma quantidade de movimentos, ou seja, 318 peças. Com isso, na etapa 2 do SLP, foi criado o diagrama de relacionamento entre as atividades, sendo possível visualizar a relação entre as áreas, conforme pode ser visto na Figura 8. Este diagrama mostra que entre o E/C e a MS ocorre uma relação ñà̀ já entre a MS e o SCI existe uma relação ñòe a relação entre as MDCE e PET é r̃Eò respectivamente.

Figura 8: Diagrama de relacionamento entre atividades

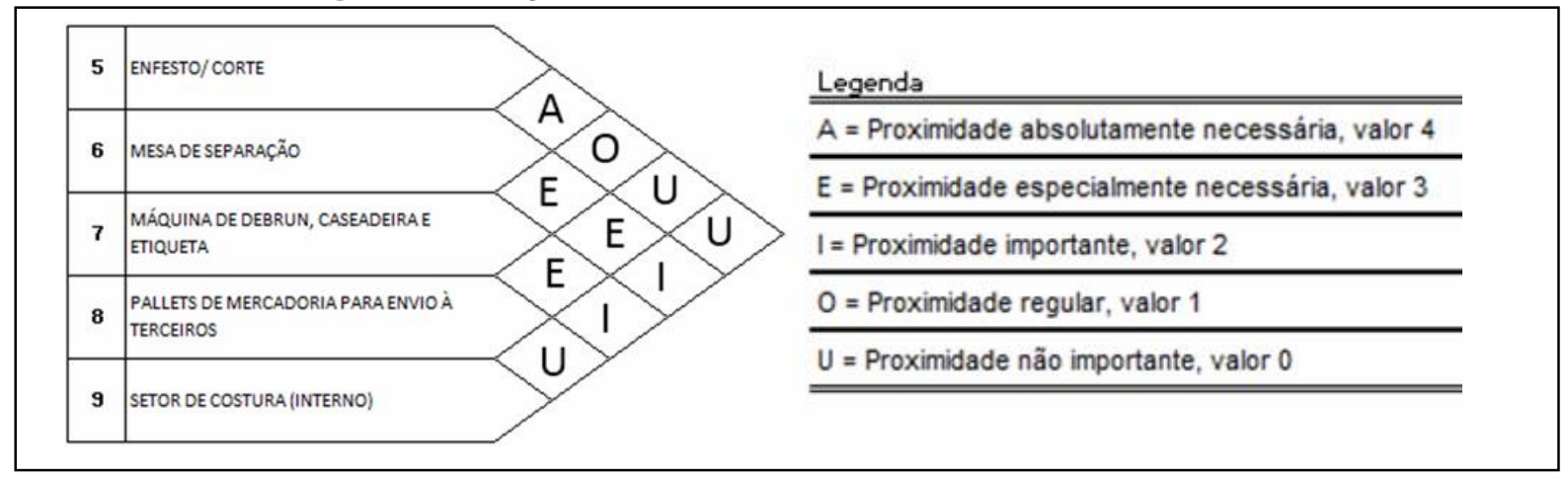

Fonte: $\mathrm{A}$ 
$\mathrm{Na}$ etapa 3 do SLP, projetou-se o local onde as áreas deveriam estar localizadas dentro do espaço existente, sendo realizado nessa etapa a avaliação dos dados e arranjo das áreas de trabalho. Nessa etapa, as letras da classificação de relação de proximidades foram substituídas por linhas. A Figura 9 mostra a disposição das áreas/máquinas do setor de corte e suas relações de proximidades. Com base na etapa anterior, mostra-se que a relação de proximidade entre o $\mathrm{E} / \mathrm{C}$ e a MS tem uma relação ñAòsendo representado por 4 linhas, e a relação entre a MS e o SCI tem relação ñò sendo representado por 2 linhas, e a relação entre as MDCE e PET tem relação rÉò sendo representado por 3 linhas por exemplo. De modo a representar as áreas/máquinas, as linhas foram substituídas por números conforme o padrão:

- 5: enfesto/corte;

- 6: mesa de separação;

- 7: máquina de debrum, caseadeira e etiqueta;

- 8: pallets de mercadoria para envio à terceiros;

- 9: setor de costura interno.

Figura 9: Diagrama de arranjo das atividades

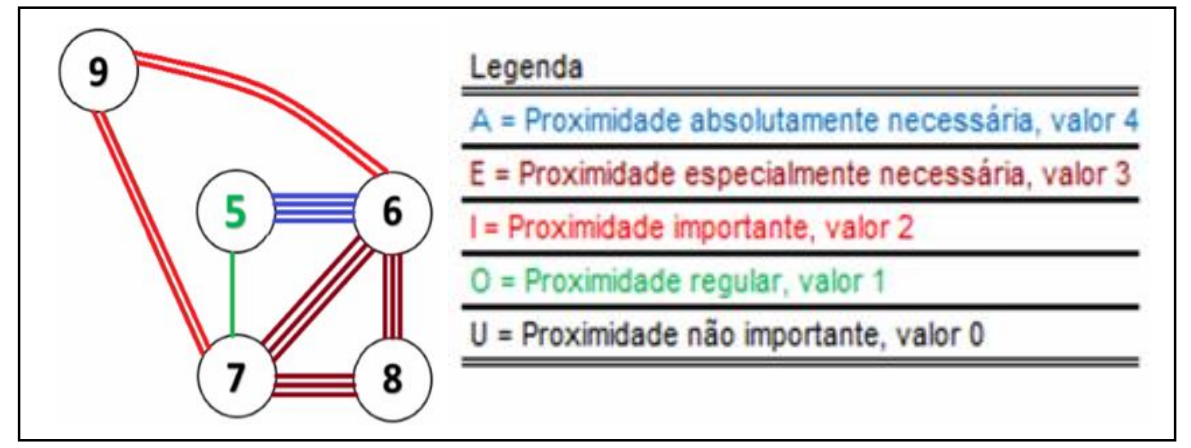

Fonte: Autores (2019)

Para a etapa 4, foi representado graficamente o plano de arranjos de espaços, conforme mostra a Figura 10, sendo as áreas representadas com retângulos proporcionais às áreas requeridas. Esse arranjo foi projetado de forma a se obter o melhor fluxo e proximidade possível entre as áreas, sendo apresentado uma menor movimentação entre os fluxos. Para a região 5, é importante destacar que foram analisados fluxos por quantidade de rolos de tecidos, pois se trata da enfestadeira, mesas de enfesto e máquina de corte. Dessa forma, a área necessária nessa análise é utilizada apenas de forma representativa. 
Para a área 6 , haverá a necessidade $7,2 \mathrm{~m}^{2}$, sendo alocada a mesa de separação dos lotes. $\mathrm{Na}$ área 7, onde está localizada a máquina de Debrum, caseadeira e etiqueta, haverá a necessidade de $7,4 \mathrm{~m}^{2}$. A área 8 , onde estão PET, haverá a necessidade de um espaço de 9,69m². Já a área 9 , onde está localizada 0 setor de corte interno da empresa, não se faz necessário o detalhamento da área necessária, uma vez que não ocupa o mesmo espaço do setor de corte, sendo que essa área foi utilizada no estudo de modo a analisar sua relação de atividades entre as demais áreas do setor de corte. Pode-se observar que, nesse arranjo, o fluxo também será linear, apresentando-se com menor movimentação entre as áreas.

Figura 10: Diagrama de relação de espaços

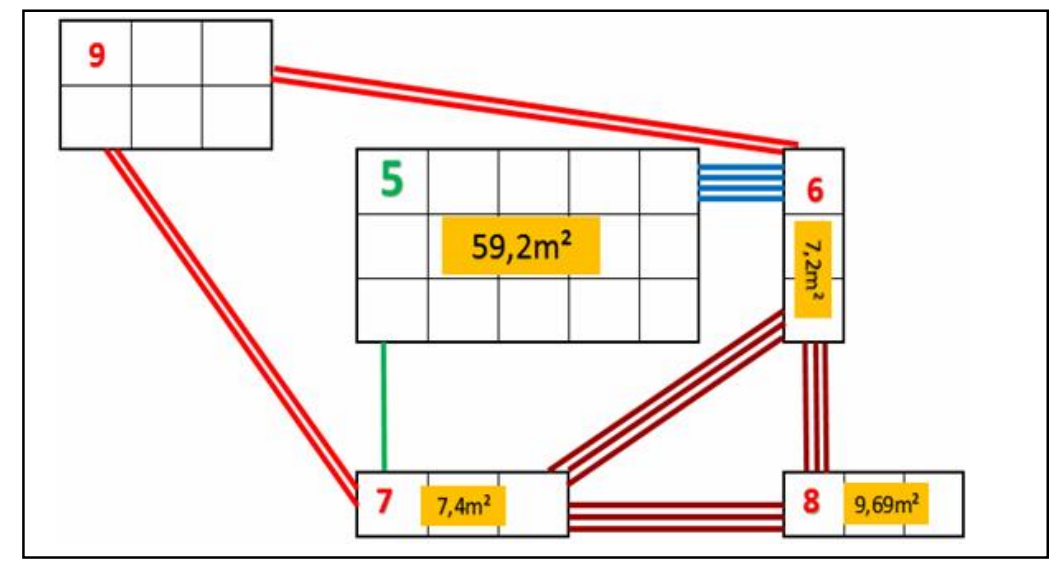

Fonte: Autores (2019)

Por fim, na etapa 5, que é a última do SLP, foi realizado o ajuste do arranjo no espaço disponível, sendo que nesta fase se levou em conta os espaços ocupados pelas demais áreas dimensionadas da empresa que não foram discutidas neste trabalho. Com isso, buscou-se o melhor arranjo, de forma a acomodar as áreas/máquinas, sendo analisadas as áreas requeridas e as prioridades de proximidade. A área 6 ficou próxima à máquina de corte (área 5), tendo seu fluxo contínuo. Também as áreas 7 e 8 ficaram próximas da área 6 , uma vez que o fluxo é maior para ambas as áreas. Já a área 9, que é o setor de corte interno, se manteve na mesma posição atual dentro do Layout atual da empresa. O detalhamento descrito pode ser observado na Figura 11. 
Figura 11: Diagrama de arranjo no espaço disponível para o setor de corte

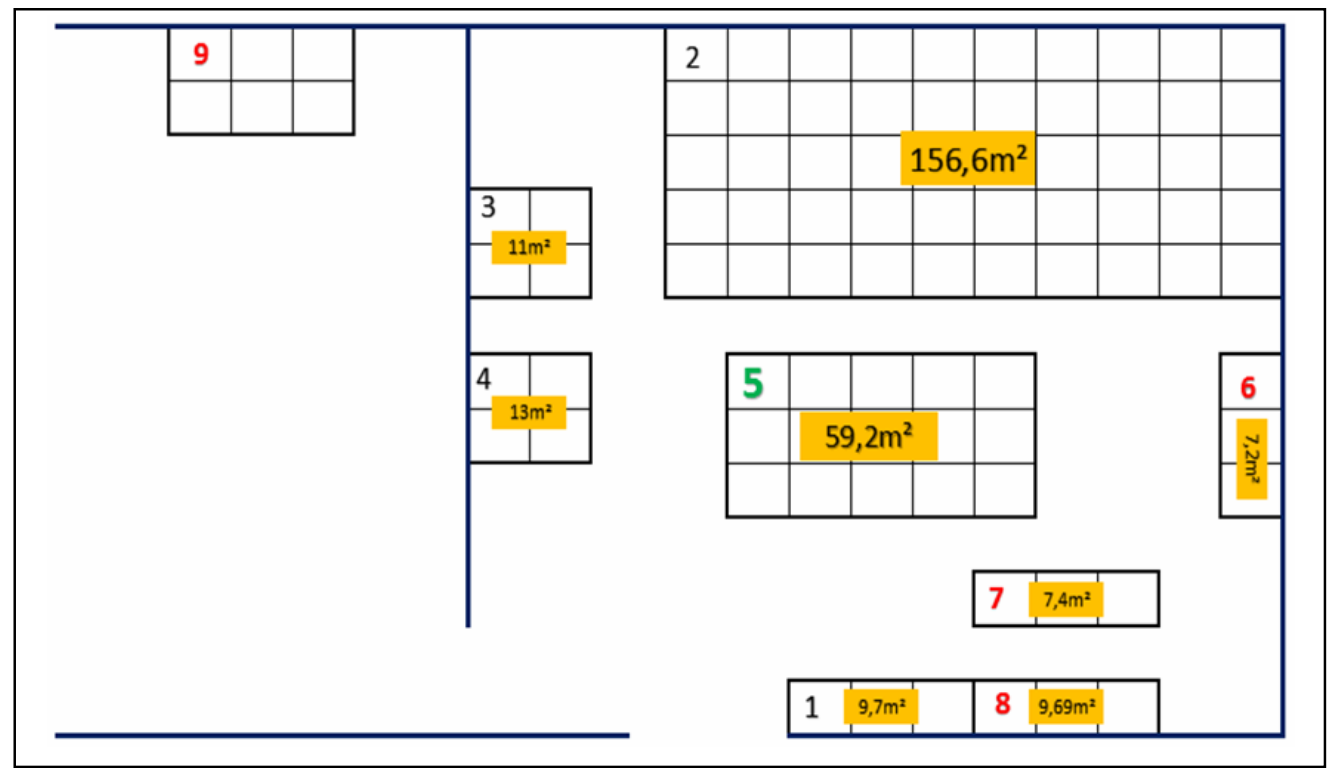

Fonte: Autores (2019)

Na representação da Figura 11, observa-se que, com o novo arranjo, haverá espaços para os corredores, bem como para os novos equipamentos. O ambiente do almoxarifado foi projetado de modo a otimizar o espaço, mantendo o dimensionamento adequado do corredor, assim projetou-se o corredor interno com $2 \mathrm{~m}$ de largura, de modo a facilitar a movimentação de armazenamento e retirada dos rolos de tecidos. Além disso, foi projetado um espaço dentro do almoxarifado para futura atividade administrativa, ou seja, uma mesa para computador e gerenciamento do estoque, conforme descrito por Martins e Laugeni (2015).

Já a mesa de separação das peças após o corte foi projetada para estar próxima à máquina de corte, de acordo com os resultados das etapas do SLP, como pode ser observado na Figura 11. Próxima à mesa de separação e à máquina caseadeira, foi mantida a prateleira de aviamentos e os pallets para envio de peças a terceiros, pois nesta área estão concentrados os materiais que são direcionados à terceirização, onde é realizada a separação dos lotes e todos os itens estão próximos, de modo a evitar movimentos desnecessários, o que vem de encontro com o objetivo do gerente de produção.

No que diz respeito ao fluxo, a Figura 11 mostra que, com a proposta do novo layout, o fluxo se apresenta de forma mais organizada no ponto de vista de movimentação, ou seja, distância percorrida dentro do processo, sendo observada uma diminuição dos movimentos de aproximadamente $23 \%$ em relação ao fluxo atual, sendo que este (considerando o material passando por somente uma mesa de 
enfesto/corte) é de aproximadamente 60,16m percorridos, desde a saída do almoxarifado até a mesa de revisão/preparação das ordens, entrada na mesa de enfesto/corte, saída da separação até o local de separação dos lotes para envio à terceirização e, por último, a saída da fábrica para terceirização.

\section{Considerações finais}

A busca pela eficiência nos processos produtivos e aumento da qualidade dos produtos é um desafio diário para as empresas, que buscam alternativas para se manterem competitivas no mercado, cada vez mais ativo e desenvolvido tecnologicamente. Assim, várias alternativas devem ser estudadas, de modo a atender os objetivos das empresas.

Nesse contexto, o presente trabalho se voltou ao estudo de um novo com o auxílio do sistema SLP, que é uma ferramenta utilizada para o planejamento e desenvolvimento de arranjos físicos, com a finalidade de alcançar a máxima eficiência possível do processo produtivo. Foi possível realizar as análises necessárias para o bom desenvolvimento do Layout proposto, de modo a propor a aproximação dos maquinários e processos com maior relação e interatividade, diminuindo, assim, a movimentação, melhor aproveitamento dos espaços, agrupamento dos equipamentos, corredores com largura recomendada por norma, entre outros. Com a aproximação dos equipamentos e fluxo contínuo e definido, não haverá a necessidade de manter estoques intermediários.

A partir dos resultados obtidos com a metodologia do sistema SLP, concluiuse que o Layout proposto é adequado ao processo produtivo da empresa. Não é possível afirmar que o Layout proposto pelo estudo será o melhor para a empresa, contudo, o resultado pode ser analisado para planejamentos futuros de seu arranjo físico, buscando a melhoria contínua de sua eficiência produtiva.

Pode-se observar no Layout proposto que o espaço interno foi aproveitado da melhor forma possível, sendo que corredores de movimentação de pessoas e materiais foram respeitados, seguindo o que é determinado pelas normas. O fluxo dentro do processo produtivo é claro e tende a minimizar o deslocamento de pessoas e matérias, sendo que os processos que possuem relação mais alta foram projetados para ficar o mais próximo possível. 
Para adequação do Layout proposto dentro do espaço disponível, é necessário que mudanças sejam realizadas, como o almoxarifado e maquinários, além de realizar pintura dos corredores e demarcação das áreas. O espaço para as máquinas existentes, bem como o espaço para os novos equipamentos, foram considerados e refletem uma melhoria na identidade visual, ou seja, é de fácil compreensão do processo, bem como se torna vantajoso para a empresa, uma vez que é possível ter uma melhor visão do processo como um todo, facilitando, assim, o gerenciamento das atividades.

Como sugestão de estudos futuros, segure-se que seja analisada a produção da empresa em um maior espaço de tempo, ou seja, procurar acompanhar a coleção inteira (3 meses), de modo a analisar se os resultados refletem o sugerido nesse estudo. Ainda como sugestão de estudo futuro, é importante destacar a necessidade de realizar uma avaliação financeira para instalação dos novos equipamentos sugeridos nesse estudo, analisando o investimento necessário. Para esta etapa, sugere-se a aplicação de métodos para análise de alternativas de investimento, como o payback (tempo de retorno), o VPL (Valor Presente Líquido) e a TIR (Taxa Interna de Retorno).

\section{Referências}

ASSUNPÇÃO, L. E.; JACOBS, W. Estudo comparativo entre layouts sob a ótica da teoria das restrições com apoio de simulação de eventos discretos em empresa de alimentos. Revista Produção Online, v. 19, p. 152-178. 2019. DOI: http://dx.doi.org/10.14488/1676-1901.v19i1.3147

CHIAVENATO, A. Introdução a Teoria Geral da Administração: 9. ed. Rio de Janeiro: Câmpus. 678 p. 2014.

CORRÊA, H. L.; CORRÊA, C. A. Administração de Produção e Operações: Manufatura e Serviços: Uma Abordagem Estratégica. 4. ed. São Paulo: Atlas. 632 p. 2017.

FLICK, U. Uma Introdução à Pesquisa Qualitativa. 3a Ed. Porto Alegre: Artmed. 2009.

GIRALDELI, F., FERREIRA, T., GOMES, P., CHIROLI, D., ZOLA, F., \& ARAGÃO, F. Estudo do fluxo de processo para readequação de layout em uma empresa do segmento elétrico. Exacta, São Paulo, v. 16, n. 4, p. 79-91. out./ dez. 2018. DOI: https://doi.org/10.5585/exactaep.v16n4.8020 
GRAEMI A. R.; PEINADO, J. Administração da Produção: Operações Industriais e de Serviços. Curitiba: Unicenp. 748 p. 2007.

MAKE, M. R. A., RASHID, M. F. F. A., \& RAZALI, M. M. A review of two-sided assembly line balancing problem. Int J Adv Manuf Technol 89: 1743. 2017. DOI: https://doi.org/10.1007/s00170-016-9158-3

MARTINS, P. G; LAUGENI, F. P. Administração da Produção: 3. ed. São Paulo: Saraiva. 584 p. 2015.

MUTHER, R. Planejamento do Layout: sistema SLP. São Paulo: Edgard Blücher. 1978.

OLIVEIRA, I. M. D.; da PAZ, C. C.; da SILVA, A. M., \& de PAULA FERREIRA, W. Balanceamento de linha e arranjo físico: estudo de caso em uma linha de produção de cabines para máquinas de construção. Exacta, 15(1), 101-110. 2017. DOI: _https://doi.org/10.5585/exactaep.v15n1.6697

SLACK, N.; JOHNSTON, R.; BRANDON-JONES, A. Administração da Produção. 4. ed. São Paulo: Atlas. 720 p. 2015.

SOULÉ, Fernanda Veríssimo et al. Proposta de redução de lead time na linha de produtos termoelétricos de uma pequena empresa familiar do interior paulista. Revista Produção Online, Florianópolis, v. 16, n. 1, p. 278-312, mar. 2016. DOI: https://doi.org/10.14488/1676-1901.v16i1.2138.

TROCHE-ESCOBAR, J. A.; CARVALHO, M. S.; FREIRES, F. G. M. O uso de tecnologias para o processo de preparação de pedidos: implicações e proposições. Revista Produção Online, v. 15, p. 188-212. 2015. DOI: http://dx.doi.org/10.14488/1676-1901.v15i1.1743

YIN, R. K. Estudo de caso: planejamento e métodos. 5.ed. Porto Alegre: Bookman. 320p. 2014. 